\title{
Mechanism of unusual polymorph transformations in calcium carbonate: Dissolution-recrystallization vs additive-mediated nucleation
}

\author{
ARPITA SARKAR and SAMIRAN MAHAPATRA* \\ Unilever R\&D, 64 Main Road, Whitefield, Bangalore 560 066, India \\ e-mail: samiran.mahapatra@unilever.com
}

\begin{abstract}
Unusual transformation of one $\mathrm{CaCO}_{3}$ phase to another has been reported by the process of dissolution-recrystallization and under the influence of additive. In one case, while metastable vaterite transforms to another metastable phase aragonite by simple refluxing in distilled water, it instead transforms thermodynamically stable phase calcite upon refluxing in its 'mother-liquor'. This is explained by the process of dissolution-recrystallization. In another case, aragonite is preferentially synthesized over calcite in the presence of molten lauric acid as an additive.
\end{abstract}

Keywords. Polymorph transformation; calcium carbonate; calcite; vaterite; aragonite; dissolution-recrystallization; additive-mediated.

\section{Introduction}

Polymorphism has tremendous technological importance due to the dependence of material properties like dissolution kinetics, hardness, density or optical properties on the solid-state structure. Polymorphism in crystalline calcium carbonate has been the focus area of research for many years. However, till date the ability to predict and control the occurrence of polymorphism during the crystallization of calcium carbonate remains as one of the key challenges. ${ }^{1,2}$ Calcium carbonate occurs as three anhydrous crystalline polymorphs (trigonal calcite, orthorhombic aragonite, and hexagonal vaterite), in two hydrated crystal forms (hexahydrate ikaite and monohydrate), and also as amorphous material. ${ }^{3-8}$ While calcite is the most thermodynamically stable form of calcium carbonate under ambient conditions, the other two anhydrous crystalline forms are metastable in nature, with vaterite being particularly/specifically unstable. ${ }^{9}$

Polymorph selection plays key role in biomineralization as the different polymorphs offer the possibility of different materials properties. Excellent examples of polymorph control are found in organisms such as mollusks, which can specifically and very selectively deposit a particular polymorph of $\mathrm{CaCO}_{3}$ (aragonite or calcite) and this process occurs under the control of biopolymers. ${ }^{10}$ For example, aragonite which provides mechanical strength is difficult to synthesize under ambient conditions but can be nucleated in the presence

*For correspondence of soluble proteins extracted from an aragonite nacre layer. ${ }^{11,12}$

Traditional strategies for selection of polymorphs in calcium carbonate often involve altering reaction conditions to influence kinetics over thermodynamic or use of additives. ${ }^{13-19}$ We have reported phase transformations based on three strategies ${ }^{20,21}$ : (i) dissolution and re-crystallization: one metastable phase to yet another metastable phase without using any additive (vaterite to aragonite), (ii) use of suitable additive: stable phase to metastable phase (calcite to aragonite/ vaterite), and (iii) thermally induced phase transition. The polymorph transformation of either vaterite to aragonite or to calcite has been explained based on the dissolution-recrystallization mechanism. In another case, lauric acid as an additive during the preparation of calcium carbonate favours the formation of aragonite over calcite.

\section{Experimental}

\subsection{Materials and experimental set-up}

$\mathrm{CaCl}_{2} \cdot 2 \mathrm{H}_{2} \mathrm{O}$ (AR grade), $\mathrm{K}_{2} \mathrm{CO}_{3}$ (anhydrous, AR grade), $\mathrm{Na}_{2} \mathrm{CO}_{3}$ (anhydrous, AR grade) were obtained from Merck (India) and were used as received. Lauric acid (99\% pure) was obtained from Loba Chemie (India). Aqueous solutions of the reactants $\left(\mathrm{CaCl}_{2} \cdot 2 \mathrm{H}_{2} \mathrm{O}, \mathrm{K}_{2} \mathrm{CO}_{3}\right.$ and $\left.\mathrm{Na}_{2} \mathrm{CO}_{3}\right)$ were made using distilled water with following characteristics: $\mathrm{pH}$ 7.2, electrical conductance $2 \times 10^{-6} \mathrm{Scm}^{-1}$, total dissolved salt $0.85 \mathrm{mg} / \mathrm{L}$, and turbidity $<0.1 \mathrm{NTU}$. 
Synthesis of calcium carbonate samples was conducted in a two-necked glass round-bottomed flask with an internal working volume of $2 \mathrm{~L}$. Mixing was performed with the help of an overhead stirrer, which was fitted with a glass rod impeller having a Teflon blade attached to it. The impeller speed for all the reactions was maintained at $350 \mathrm{rpm}$. Reactants were added through the side neck of the two-necked roundbottomed flask, and the rate of addition was controlled at $10 \mathrm{ml} / \mathrm{min}$ with the help of a peristaltic pump (manufacturer: Trishul Equipments, Bhandup, Mumbai). Heating was performed with the help of a temperature-controlled heating mantle.

\subsection{Synthesis of different $\mathrm{CaCO}_{3}$ samples in absence of any additive}

2.2a Preparation of pure vaterite: Pure vaterite sample was prepared as described earlier. ${ }^{20}$ An aqueous solution of $\mathrm{CaCl}_{2} \cdot 2 \mathrm{H}_{2} \mathrm{O}$ was added to an aqueous solution of $\mathrm{K}_{2} \mathrm{CO}_{3}$ whose temperature was maintained at $30^{\circ} \mathrm{C}$. The precipitate was filtered, washed thoroughly with distilled water, and then dried at room temperature for about $24 \mathrm{~h}$ in a vacuum desiccator containing anhydrous $\mathrm{CaO}$. This material was obtained as a dense free-flowing white powder. Yield: $48 \mathrm{~g}$ (96\%). The filtrate obtained after separation of the precipitate was collected separately and labelled as 'mother liquor' and kept aside for other experiments.

$2.2 \mathrm{~b}$ Preparation of aragonite samples from the vaterite precursor: About $10 \mathrm{~g}$ of the pure vaterite sample as described above was dispersed in $500 \mathrm{~mL}$ distilled water in a round-bottom flask and was refluxed at $100{ }^{\circ} \mathrm{C}$ for different time periods. After cooling to room temperature, the solid mass was filtered through Whatman ${ }^{\circledR} 40$ filter paper, washed thoroughly with distilled water, and then dried at room temperature for about $24 \mathrm{~h}$ in a vacuum desiccator containing anhydrous $\mathrm{CaO}$. The samples were found to be either a mixture of vaterite/aragonite or $100 \%$ aragonite depending on the duration of reflux. ${ }^{20}$

2.2c Preparation of calcite samples from the vaterite precursor: Pure vaterite sample as described was refluxed with the 'mother liquor' for different duration period. After cooling to room temperature, the solid mass was filtered through Whatman ${ }^{\circledR} 40$ filter paper, washed thoroughly with distilled water, and then dried at room temperature for about $24 \mathrm{~h}$ in a vacuum desiccator containing anhydrous $\mathrm{CaO}$. The samples were found to be either a mixture of vaterite/calcite or $100 \%$ calcite depending on the refluxing time. ${ }^{20}$

\subsection{Synthesis of different $\mathrm{CaCO}_{3}$ samples in presencelabsence of lauric acid}

2.3a Preparation of pure calcite in absence of lauric acid: Pure vaterite sample was prepared as described earlier. ${ }^{21}$ An aqueous solution of $\mathrm{Na}_{2} \mathrm{CO}_{3}$ was added to an aqueous $\mathrm{CaCl}_{2} \cdot 2 \mathrm{H}_{2} \mathrm{O}$ solution whose temperature was maintained at $45^{\circ} \mathrm{C}$. The precipitate was filtered and washed thoroughly with distilled water, dried at $\sim 60^{\circ} \mathrm{C}$ in a vacuum oven and was then kept in a vacuum desiccators containing fused $\mathrm{CaCl}_{2}$ for $24 \mathrm{~h}$. The dried mass was ground to a powder using a mortar and pestle.

2.3b Preparation of $\mathrm{CaCO}_{3}$ in presence of lauric acid: An aqueous solution of $\mathrm{Na}_{2} \mathrm{CO}_{3}$ was added to a mixture of an aqueous $\mathrm{CaCl}_{2} \cdot 2 \mathrm{H}_{2} \mathrm{O}$ solution and molten lauric acid heated to $45{ }^{\circ} \mathrm{C} .{ }^{21}$ The precipitate was filtered, washed several times with ethanol to remove any unreacted fatty acid, then dried at $\sim 60^{\circ} \mathrm{C}$ for about $4 \mathrm{~h}$ in a vacuum oven and was then kept in a vacuum dessicator containing fused $\mathrm{CaCl}_{2}$ for $24 \mathrm{~h}$. The dried mass was ground to a powder using a mortar and pestle.

\subsection{Characterization techniques}

The Powder X-ray Diffraction patterns were recorded on a Siemens D-5000 diffractometer using $\mathrm{Cu}-\mathrm{K} \alpha(\alpha=$ $1.5406 \AA$ ) radiation. The $0.02^{\circ}$ steps and the $2 \theta$ range from $20^{\circ}$ to $60^{\circ}$ were selected to analyse the crystal structure. The percentage of each polymorph of calcium carbonate was calculated from their characteristic XRD peak intensities by using following formula as described in the literature. ${ }^{22}$

$$
\begin{gathered}
X_{A}=\frac{3.157\left(I_{A}^{221}\right)}{I_{C}^{104}+3.157\left(I_{A}^{221}\right)+7.691\left(I_{v}^{110}\right)} \quad X_{v}=1-X_{A}-X_{C}, \\
X_{v}=\frac{7.691\left(I_{v}^{110}\right)}{I_{C}^{104}+7.691\left(I_{v}^{10}\right)} \quad X_{C}=1-X_{v}, \\
\frac{I_{C}^{104}}{I_{A}^{221}}=3.157 \times \frac{X_{C}}{X_{A}} .
\end{gathered}
$$

In the above formulas, $X_{A}, X_{C}$ and $X_{V}$ are the molar fractions of aragonite, calcite and vaterite in a mixture, respectively. The intensities of the peaks of the 221 plane of aragonite, the 104 plane of calcite and the 110 plane of vaterite are represented as $I_{A}^{221}, I_{C}^{104}$ and $I_{V}^{110}$, respectively.

The Fourier transformed infrared (FTIR) measurements were performed on a Bomem FTIR spectrophotometer (Model: MB 102) with a resolution of $2 \mathrm{~cm}^{-1}$. 


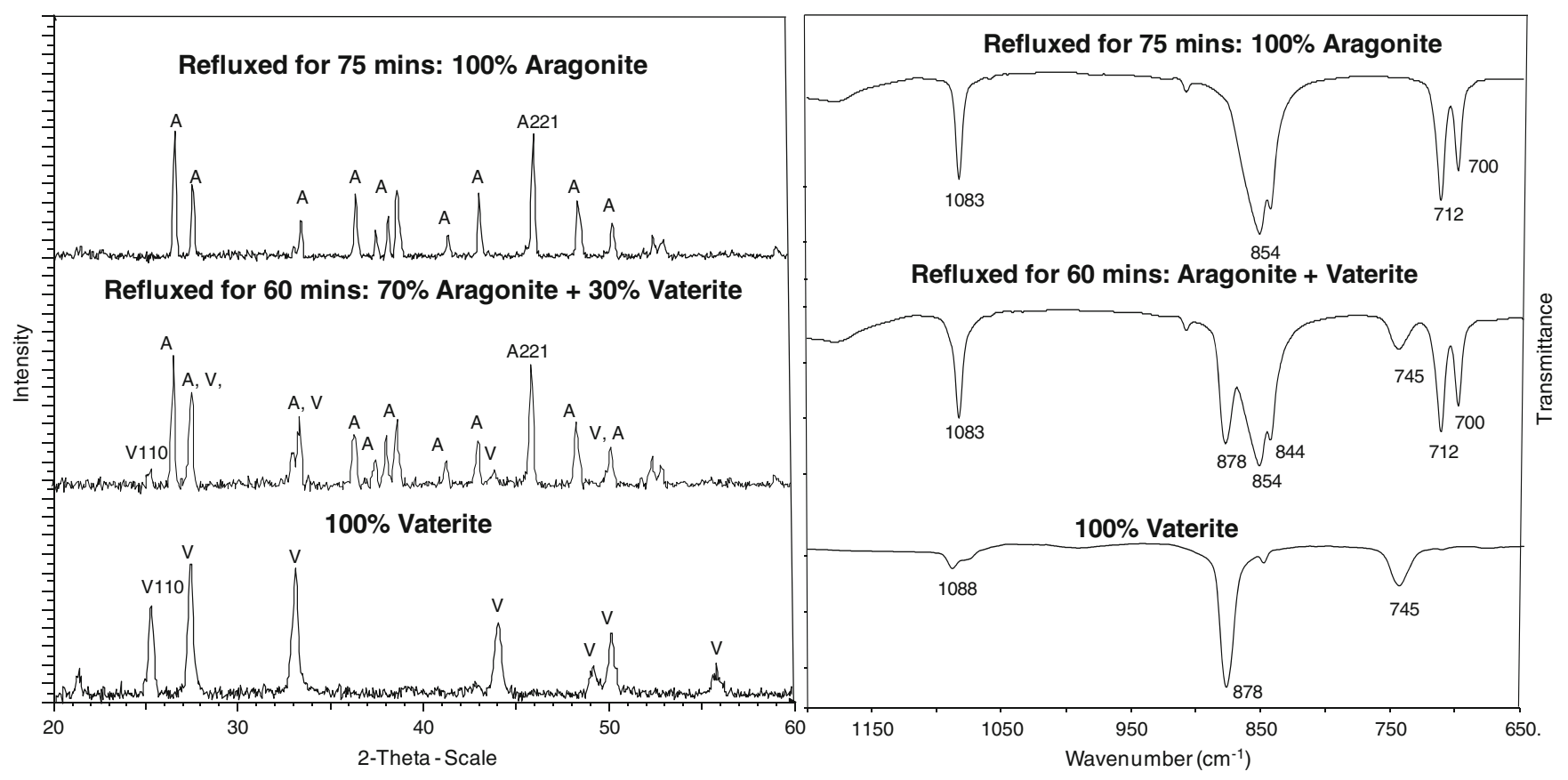

Figure 1. Vaterite to aragonite transformation by refluxing in de-ionized water, as monitored using powder XRD and FTIR. [* $\mathrm{A}$ and $\mathrm{V}$ denote aragonite and vaterite, respectively, $\mathrm{A}^{221}$ and $\mathrm{V}^{110}$ denotes the intensities of the peaks of the 221 plane of aragonite and the 110 plane of vaterite, respectively.]

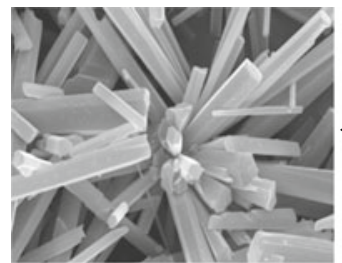

Aragonite

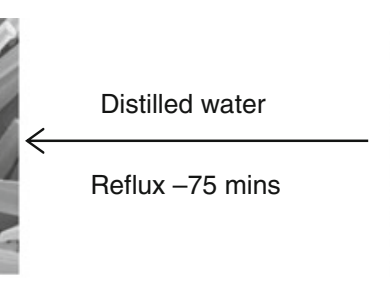

Scheme 1. Scheme of phase transformation: dissolution and re-crystallization pathway.
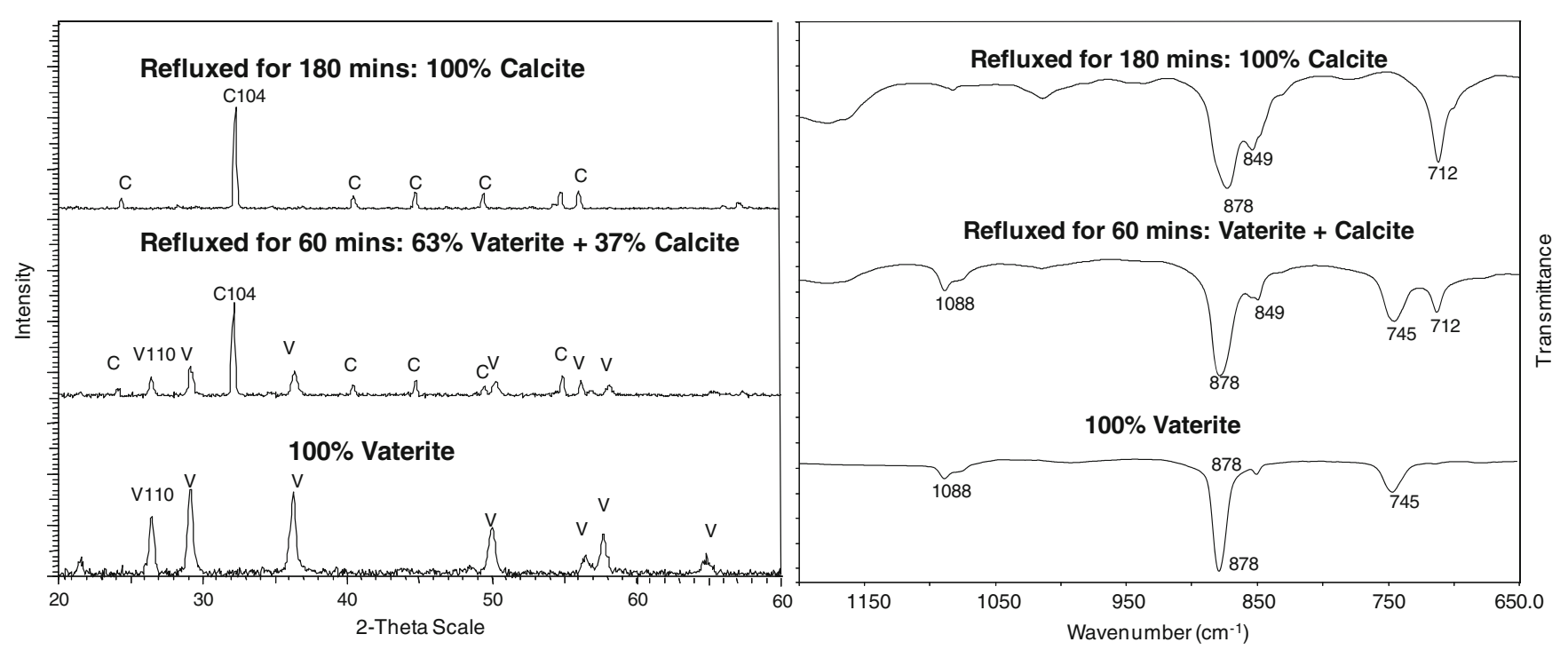

Figure 2. Vaterite to calcite transformation by refluxing in 'mother liquor' as monitored by XRD and FTIR. [* C and V denote calcite and vaterite, respectively, $\mathrm{C}^{104}$ and $\mathrm{V}^{110}$ denotes the intensities of the peaks of the 104 plane of calcite and the 110 plane of vaterite, respectively.] 

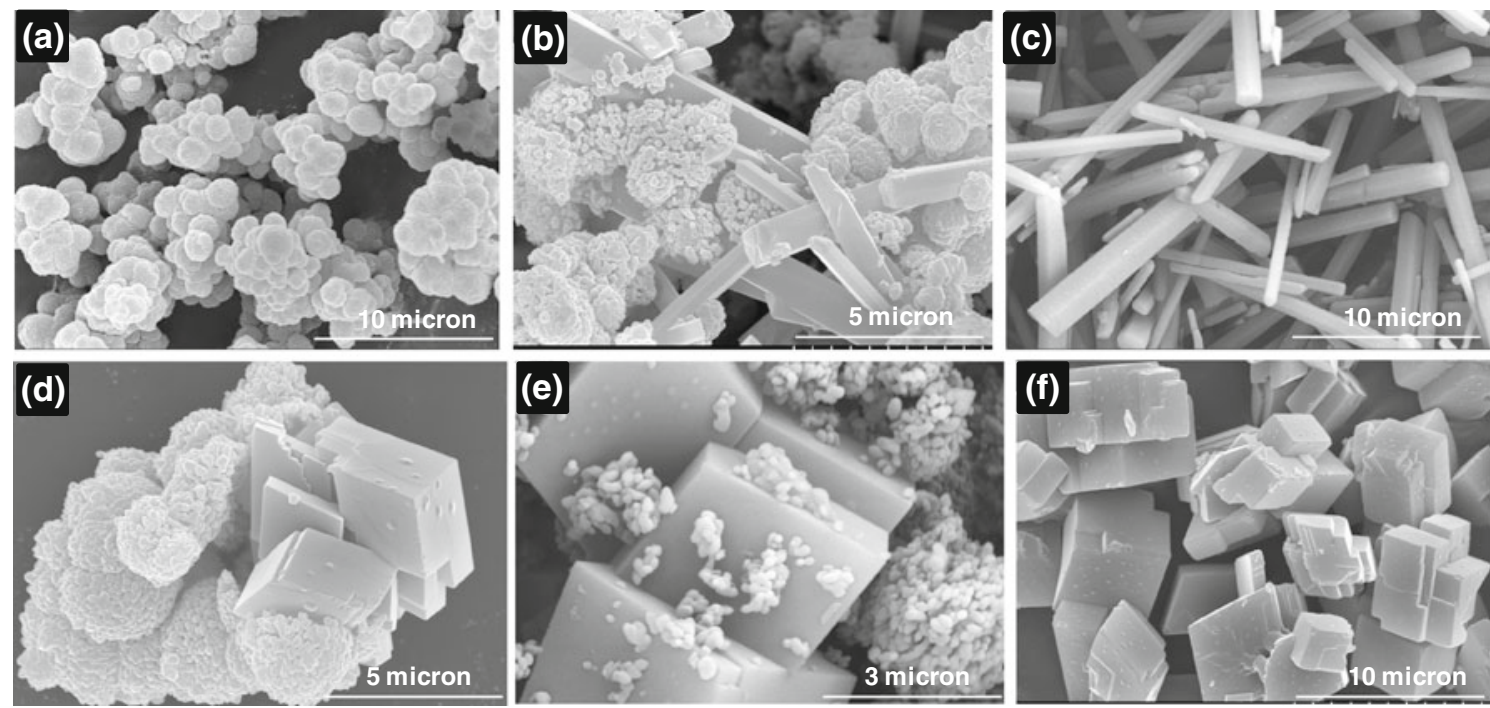

Figure 3. SEM images of the samples: (a) pure vaterite, (b) intergrowth of vaterite and aragonite, (c) pure aragonite, $(\mathbf{d}, \mathbf{e})$ inter-growth of calcite and vaterite, and (f) pure calcite.

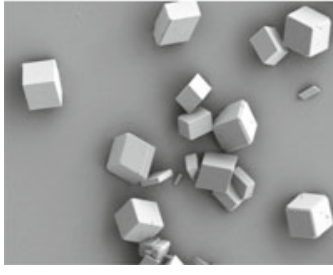

Calcite
No additive

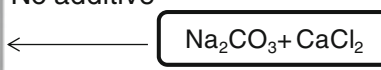

In presence of Lauric Acid

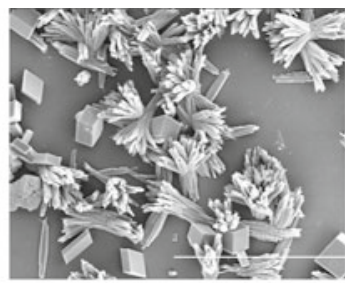

Calcite + Aragonite

Scheme 2. Scheme of phase transformation: additive mediated.

Pressed pellets of the samples diluted with potassium bromide ( $2 \mathrm{mg}$ in $200 \mathrm{mg}$ ) were used.

Scanning electron micrographs (SEM) of the powder samples were taken on a Hitachi S-4700 scanning electron microscope fitted with a field emission source and with an accelerating voltage of $20 \mathrm{kV}$. Samples were uniformly spread on double sided carbon wafer tapes and gold-coated prior to microscopy experiments.

\section{Results and discussion}

\subsection{Polymorph transformation via dissolution-recrystallization}

Pure vaterite phase was synthesized by reacting equal volumes of equimolar solutions of $\mathrm{K}_{2} \mathrm{CO}_{3}$ and $\mathrm{CaCl}_{2}$.

$$
\mathrm{CaCl}_{2}+\mathrm{K}_{2} \mathrm{CO}_{2} \rightarrow \mathrm{CaCO}_{3}+2 \mathrm{KCl}
$$

Initially, gel-like amorphous phase was detected which was transient and transformed within a few minutes into the crystalline phase. The purity of the vaterite phase was characterized from its XRD and FTIR spectra. Morphology of the crystals was ascertained by SEM imaging. Phase transformation to aragonite was achieved by refluxing the vaterite in distilled water

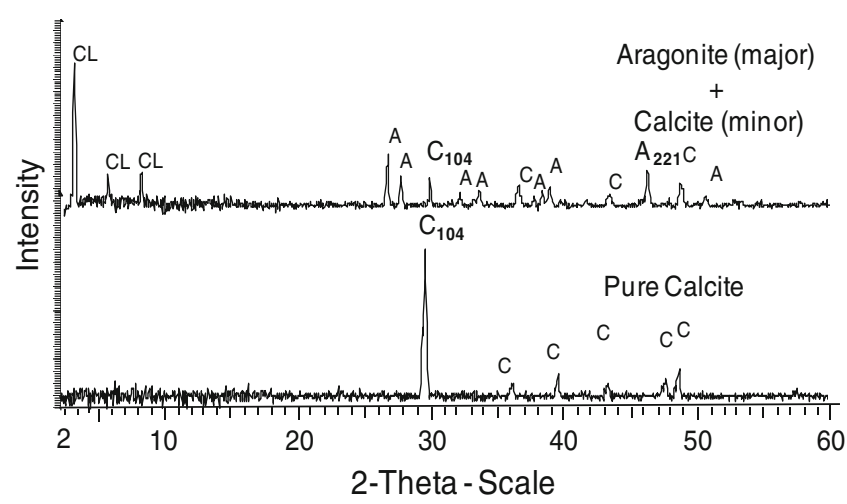

Figure 4. XRD pattern of $\mathrm{CaCO}_{3}$ sample prepared in the absence (pure calcite) and in the presence of lauric acid (80\% aragonite $+20 \%$ calcite) [* A and C denote aragonite and calcite, respectively, $\mathrm{A}^{221}$ and $\mathrm{C}^{104}$ denote the intensities of the peaks of the 221 plane of aragonite and the 104 plane of calcite, respectively. CL denotes the intensities of the peaks of calcium laurate.] 

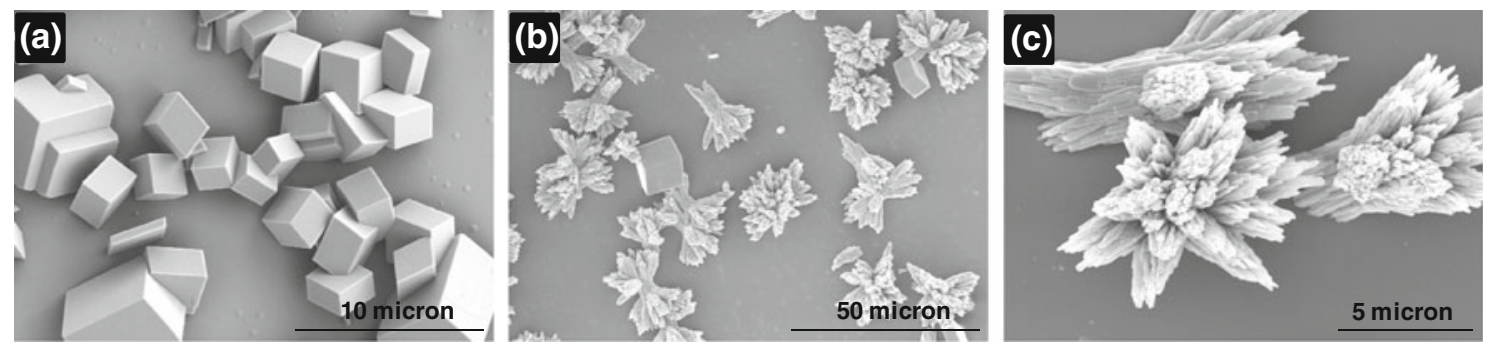

Figure 5. SEM images of $\mathrm{CaCO}_{3}$ samples prepared (a) calcite particles in the absence of lauric acid and $(\mathbf{b}, \mathbf{c})$ mixture of calcite and aragonite particles formed in the presence of lauric acid.

for at least $75 \mathrm{~min}$. Aliquots were withdrawn at intermediate time intervals to monitor the progress of the phase transformation. The inter-growth of phases and the fully transformed phase were characterized by XRD and FTIR (figure 1). The relative percentage of each polymorph of calcium carbonate was calculated from their characteristic XRD peak intensities by using the formula as reported in the literature. ${ }^{22}$ SEM images showed intergrowth of vaterite and aragonite in the intermediate samples; calcite was not detected during this course of phase transformation. Based on the solubility of different phases ${ }^{23}$, dissolution and re-crystallization pathway for the above phase transformation has been proposed (scheme 1). ${ }^{20}$

On the other hand, calcite phase was obtained when the same vaterite sample was refluxed in the 'mother liquor' for at least $180 \mathrm{~min}$. In this case also, aliquots were withdrawn at intermediate time intervals and were characterized. Both XRD and FTIR studies revealed that transformation to calcite happened without going through an intermediate aragonite phase (figure 2). All the intermediate samples had inter-growths of calcite and vaterite that further strengthened the dissolution and re-crystallization pathway for the following phase transformation (figure 3).

This particular course of phase transformation has been depicted in scheme 1 .

\subsection{Additive mediated polymorph control and phase transformation}

Pure calcite phase was synthesized by reacting equal volumes of equimolar solutions of $\mathrm{Na}_{2} \mathrm{CO}_{3}$ and $\mathrm{CaCl}_{2}$ at $45^{\circ} \mathrm{C}$. The order of addition was carbonate solution being added to $\mathrm{CaCl}_{2}$ solution. On the other hand, when the carbonate solution was added to a mixture of $\mathrm{CaCl}_{2}$ and molten lauric acid, a mixture of calcite and aragonite phases were obtained (scheme 2). Increasing the amount of lauric acid led to an increase in the percentage of aragonite. ${ }^{21}$ Thus, lauric acid has initiated the phase transformation from thermodynamically stable calcite to metastable aragonite phase. The phases were characterized from their XRD and FTIR patterns (figure 4). Moreover, lauric acid has also promoted a change in morphology from rhombohedral (calcite in the absence of any additive) to rosette shaped aragonite particles (figure 5). These rosette shaped particles were comprised of an aggregation of nano-aragonite rods. Lauric acid complexes with calcium to form calcium laurate (as evidenced from FTIR), which acts as a seed agent to nucleate preferentially aragonite instead of calcite.

\section{Conclusion}

Predicting and controlling a specific polymorph of calcium carbonate is a long-standing challenge. Traditional strategies for selection of polymorphs in calcium carbonate often involve altering reaction conditions to influence kinetics over thermodynamic or vice versa, although use of additives is also a common strategy. We have reported the stabilization of metastable calcium carbonate phases at ambient conditions in one case without the use of any additives. Metastable vaterite has been transformed to both aragonite and calcite separately, transformation occurred via dissolution and recrystallization. In another case, the course of phase transformation was shifted from thermodynamically stable calcite to metastable aragonite by means of lauric acid as an additive during the reaction.

\section{References}

1. Meldrum F C and Colfen H 2008 Chem. Rev. 1084332

2. Politi Y, Arad T, Klein E, Weiner S and Addadi L 2004 Science 3061161

3. Brecevic L and Nielsen A E 1989 J. Cryst. Growth. 98 504

4. Clarkson J R, Price T J and Adams C J 1993 J. Chem. Soc. Faraday Trans. 88243

5. Hesse K F, Kueppers H and Suess E 1983 Z. Kristallogr. 163227 
6. Neumann M and Epple M 2007 Eur. J. Inorg. Chem. 1953

7. Aizenberg J, Lambert G, Addadi L and Weiner S 1996 Adv. Mater. 8222

8. Addadi L, Raz S and Weiner S 2000 Adv. Mater. 15 959

9. Colfen H 2003 Curr. Opin. Colloid Interface Sci. 8 23

10. Addadi L, Joester D, Nudelman F and Weiner S 2006 Chem. Eur. J. 12981

11. Belcher A M, Wu X H, Christensen R J, Hansma P K, Stucky G D and Morse D E 1996 Nature 38156

12. Falini G, Albeck S, Weiner S and Addadi L 1996 Science 27167

13. Zhang L, Yue L H, Wang F and Wang Q 2008 J. Phys. Chem. B 11210668

14. Gebauer D, Colfen H, Verch A and Antonietti M 2009 Adv. Mater. 21435
15. Falini G, Fermani S, Tosi G and Dinelli E 2009 Cryst. Growth Des. 92065

16. Xu AW, Dong W F, Antonietti M and Colfen H 2008 Adv. Funct. Mater. 181307

17. Naka K, Keum D K, Tanaka Y and Chujo Y 2000 Chem. Commun. 1537

18. Dickinson S R and McGrath K M 2003 J. Mater. Chem. 13928

19. Chakrabarty D and Mahapatra S 1999 J. Mater. Chem. 9 2953

20. Sarkar A and Mahapatra S 2010 Cryst. Growth Des. 10 2129

21. Sarkar A, Ghosh A K and Mahapatra S 2012 J. Mater. Chem. 2211113

22. Kontoyannis C G and Vagenas N V 2000 Analyst 125 251

23. Brecevic L and Nielsen A E 1989 J. Cryst. Growth. 98 504 